\title{
Spatiotemporal analysis of reported cases of acute Chagas disease in the State of Pernambuco, Brazil, from 2002 to 2013
}

\author{
Fred Luciano Neves Santos ${ }^{[1],[2], ~ V i r g i n i a ~ M a r i a ~ B a r r o s ~ d e ~ L o r e n a ~}{ }^{[1],[2],}$ \\ Wayner Vieira de Souza ${ }^{[3]}$ and Yara de Miranda Gomes ${ }^{[1,[2]}$
}

[1]. Serviço de Referência em Doença de Chagas, Centro de Pesquisas Aggeu Magalhães, Fundação Oswaldo Cruz, Recife, Pernambuco, Brasil. [2]. Programa Integrado de Doença de Chagas, Fundação Oswaldo Cruz, Rio de Janeiro, Brasil. [3]. Departamento de Saúde Coletiva. Centro de Pesquisas Aggeu Magalhães, Fundação Oswaldo Cruz, Recife, Pernambuco, Brasil.

\begin{abstract}
Introduction: Control strategies to eliminate the transmission of Chagas disease by insect vectors have significantly decreased the number of reported acute cases in Brazil. However, data regarding the incidence and distribution of acute Chagas disease cases in the State of Pernambuco are unavailable in the literature. Methods: A geographical information system was used to delineate the spatiotemporal distribution profile of the cases from 2002 to 2013 in 185 municipalities of Pernambuco based on the municipality where notification occurred. The results were presented in digital maps generated by the TerraView software (INPE). Results: A total of 302 cases of acute disease were recorded in $37.8 \%$ of the municipalities, for a total of 0.13 cases per $1,000,000$ inhabitants per year. Out of the 302 cases, 99.3\% were reported between 2002 and 2006. The most affected municipalities were Carnaubeira da Penha, Mirandiba and Terra Nova. The risk maps showed a significant decrease in the number of notifications and a concentration of cases in the Midwest region. Conclusions: This study highlights a significant decrease in new cases of acute Chagas disease in Pernambuco starting in 2006 when Brazil received an international certification for the interruption of vectorial transmission by Triatoma infestans. However, control strategies should still be encouraged because other triatomine species can also transmit the parasite; moreover, other transmission modes must not be neglected.
\end{abstract}

Keywords: Chagas disease. Spatiotemporal analysis. Pernambuco. Brazil.

\section{INTRODUCTION}

American trypanosomiasis, or Chagas disease, is a zoonosis caused by the hemoflagellate parasite Trypanosoma cruzi that is transmitted to humans by a blood-sucking triatomine bug through the insect's infected feces while it is feeding on blood. Parasites within the triatomine feces may enter the human body through either broken skin or mucous membranes, including the conjunctiva or oral/digestive mucosa. In addition, outbreaks caused by contaminated food may occasionally occur ${ }^{(1)}$. Alternative and less frequent routes of transmission include blood transfusion, organ transplantation and maternal-fetal transmission ${ }^{(2)}$. Infection with $T$. cruzi represents a serious problem among less-favored populations, and this transmission method is frequently associated with poverty and marginalization in rural areas. Chagas disease

Corresponding author: Dr. Fred Luciano Neves Santos. Serviço de Referência em Doença de Chagas/CPqAM/FIOCRUZ. Av Professor Moraes Rego s/n, Campus da UFPE, 55740-465 Recife, Pernambuco, Brasil.

Phone: 5581 2101-2682

e-mail: fred.santos@cpqam.fiocruz.br

Received 22 December 2014

Accepted 31 March 2015 causes mortality in 14,000 people and morbidity in up to 10 million people in Latin American, resulting in a substantial disease burden in 21 endemic countries ${ }^{(3)(4)(5)}$. Despite control efforts over the past 100 years since its discovery, this disease continues to represent a world threat due to international migrations, making it increasingly frequent in non-endemic countries ${ }^{(3)}$.

Over 130 species have been identified as potential vectors of $T$. cruzi. In Brazil, 52 species of triatomines have been described, and the following five species have particular epidemiological importance because of their domestic habitats: Triatoma infestans, Panstrongylus megistus, Triatoma brasiliensis, Triatoma pseudomaculata and Triatoma sordida. Control measures adopted by South American countries have resulted in a significant decrease in the number of acute cases. The Southern Cone Initiative (SCI) was created in 1991 by the governments of Argentina, Bolivia, Brazil, Chile, Paraguay, and Uruguay and is associated with compulsory screening of blood banks. This initiative has been extremely important for Chagas disease control in this region. The basic aim of the SCI was to stop disease transmission, primarily by eliminating the main vector, $T$. infestans, which is the only strictly domesticated species, and by screening safe donors in regional blood banks ${ }^{(6)}$. Nevertheless, data from the Brazilian Ministry of Health showed 
2,476 reported cases of acute Chagas disease in Brazil from 2001 to $2006^{(7)}$. Although several Latin America countries, including Brazil, received the Pan American Health Organization/ World Health Organization (PAHO/WHO) certification of the interruption of vectorial transmission via T. infestans in $2006^{(8)}$, attention should be directed to new cases of Chagas disease that occur due to both contaminated food and beverages in endemic areas and other triatomine species able to transmit the parasite. In 2000, the interruption of vectorial transmission of T. cruzi by T. infestans in Pernambuco was reported ${ }^{(9)}$. However, new acute cases have been reported in all Brazilian regions ${ }^{(7)}$.

Studies of the occurrence of infectious diseases according to their spatial distribution have been deemed important for public health, especially for planning and executing disease control measures ${ }^{(10)}$. Geographic Information Systems (GIS) have contributed to the effectiveness of actions through the analysis of spatial data on health parameters, revealing priority areas for interventions ${ }^{(11)}$. The use of this tool for monitoring vector-borne diseases such as Chagas disease may allow for the identification of the spatiotemporal distribution profile of disease incidence or mortality in defined geographic regions ${ }^{(12)}$. In the present study, we describe the spatiotemporal distribution profile of acute Chagas disease in Pernambuco according to the municipality of notification from 2002 to 2013.

\section{METHODS}

\section{Study area}

The study was performed in the State of Pernambuco (PE), Brazil. PE is located in the Northeast region ( $8^{\circ} 4^{\prime} 14^{\prime \prime} \mathrm{S}, 37^{\circ}$ $\left.15^{\prime} 57^{\prime \prime} \mathrm{W}\right)$, and its proximity to the Equator guarantees sunshine throughout the year, with average temperatures of $26^{\circ} \mathrm{C}\left(79^{\circ} \mathrm{F}\right)$. The state is considered a geographically diverse region due to its size, relief, climate, and natural resources, and it is currently divided into 5 mesoregions (São Francisco, Sertão, Agreste, Zona da Mata and Metropolitana) and 185 municipalities. The municipalities are legally autonomous territorial areas and are the smallest autonomous units of the Federation.

\section{Study population and design}

We performed a retrospective ecological study through spatiotemporal analysis using reported acute Chagas disease cases aggregated according to the municipality of notification. We included all reported cases of acute Chagas disease in 185 Pernambuco municipalities from 2002 to 2013. Data were retrieved from the Information System for Notifiable Diseases [Sistema de Informação de Agravos de Notificação (SINAN)] of the Brazilian Ministry of Health. SINAN data are publicly available and were obtained from the website of the Department of Informatics of the Unified Health System [Departamento de Informática do Sistema Único de Saúde (DATASUS), available at http://dtr2004.saude.gov.br/sinanweb]. This database represents an important source of information for the construction of indicators for monitoring the temporal dynamics of notifiable diseases in Brazil and provides supporting elements for the development of prevention and control activities.
Data sets for each municipality and year were obtained for acute cases of Chagas disease. Other variables evaluated in this study included age, sex and race. Consequently, several data sets were downloaded and processed. Population data for the same period were obtained from Brazilian Institute of Geography and Statistics [Instituto Brasileiro de Geografia e Estatística (IBGE)] and were based on national census data from 2000 and 2010 and official estimates for the other years (available at http://www.ibge.gov.br).

\section{Data analysis}

Spatial analysis methods and GIS techniques were used to evaluate the geographic distribution of acute Chagas disease in the State of Pernambuco. We analyzed data from areas and adopted the municipality of notification as a unit of analysis to obtain better accuracy regarding the differences within and among regions. Construction of the spatial distribution maps was based on the moving averages by applying three-year intervals to data from 2002 to 2013; this method was also used to minimize random fluctuation effects in a time-series of rates calculated for rare events. The annual incidence rate was calculated for 185 municipalities and the whole State by standard methods. To assess the relative risk of acute Chagas disease for each municipality, maps were constructed using the moving average for the first 3-year rate in Pernambuco as the denominator and assuming no changes in time and space.

Digital maps were obtained from the cartographic basis of IBGE in shape file (.shp) format, which is compatible with the Terra View software, version 4.2, developed by the National Institute for Space Research [Instituto Nacional de Pesquisas Espaciais (INPE)]. This software package was used for the processing, analysis and presentation of cartographic data as well as for the calculation of risk area indicators and the construction of thematic maps.

\section{Ethical considerations}

This study was based on secondary data, and all of the information used is public domain. No variables allowed the identification of any individuals.

\section{RESULTS}

\section{Spatial distribution of acute Chagas disease}

Between 2002 and 2013, 302 acute Chagas disease cases were reported. Out of 185 municipalities, 70 (37.8\%) reported at least one case of acute Chagas disease during this period. The mean rate of reported cases in Pernambuco was 0.13 per $1,000,000$ inhabitants per year, ranging from 0.0 to 7.32 reported cases per 1,000,000 inhabitants. The mean rate of reported cases in the country was 0.12 per $1,000,000$ inhabitants per year (varying from 0.80 to 3.03). Compared to data from Brazil, Pernambuco showed a higher three-year moving average of cases for the first seven years of the study period. However, over the time period evaluated, Pernambuco has shown a decrease in the number of reported acute cases (Figure 1). In the first four years (2003 to 2006), the estimated incidence 


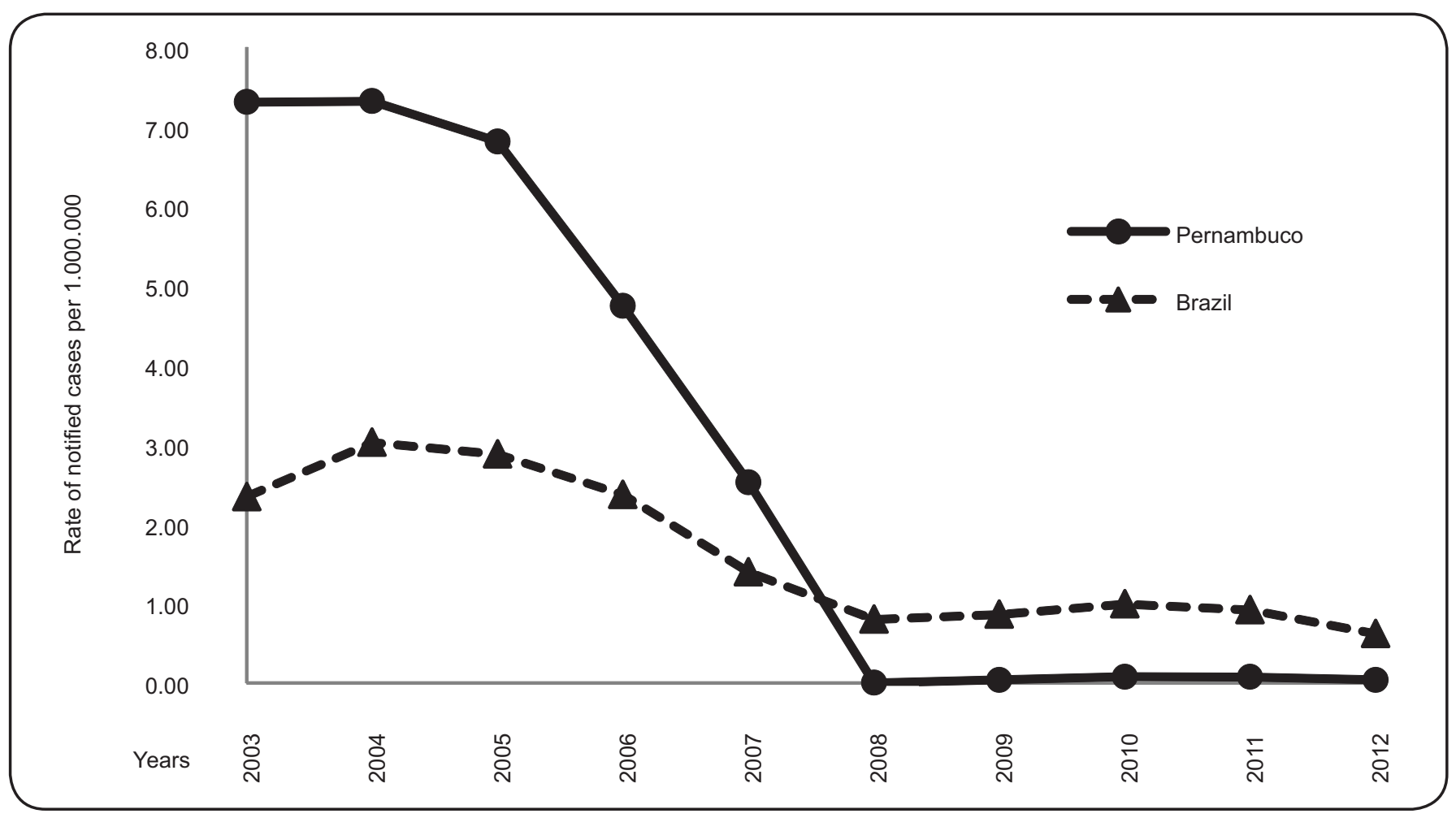

FIGURE 1 - Rate of reported cases of acute Chagas disease in Brazil and State of Pernambuco (per 1,000,000 inhabitants) from 2002 to 2013 (moving average) according to SINAN records. SINAN: Sistema de Informação de Agravos de Notificação.

for Pernambuco was 6,534 per $1,000,000$, and the incidence decreased significantly to 0.045 in the last period (2008 to 2012).

The socio-demographic characterization of acute cases showed $130(43 \%)$ males and $172(57 \%)$ females, with the majority of the reported cases aged between 20 and 59 years. Table 1 shows the heterogeneous distribution of the reported cases of acute Chagas disease by race. The most affected race was brown (multiracial) (49\%). It is noteworthy that $15(5 \%)$ reported cases were Amerindians.

The spatiotemporal distribution of acute Chagas disease rates at ten different time points is depicted in Figure 2. Overall, the first three figures (Figures 2 - maps 2003, 2004 and 2005) clearly show a concentration of high-incidence municipalities in the central west region of Pernambuco, more precisely in the City of Carnaubeira da Penha (São Francisco Pernambuco mesoregion), and in other municipalities of the Sertão Pernambucano mesoregion (Mirandiba, Salgueiro and Serrita), with an incidence higher than 10 cases per 100,000 inhabitants. Some areas of the Agreste Pernambucano region were also affected, varying from 7 to 20 cases per 100,000 inhabitants (Iati, Correntes and Palmerina). In addition, between 2006 and 2008 there were some small areas with high case notifications, notably in Alagoinha, Altinho, Correntes and Brejão (Agreste Pernambucano mesoregion), Mirandiba, Terra Nova (Sertão Pernambucano mesoregion) and Carnaubeira da Penha (São Francisco Pernambuco mesoregion) (Figures 2 - maps 2006, 2007 and 2008). Conversely, few cases were reported

TABLE 1 - Reported acute Chagas disease cases in State of Pernambuco, Brazil, 2002-2013, distributed by race.

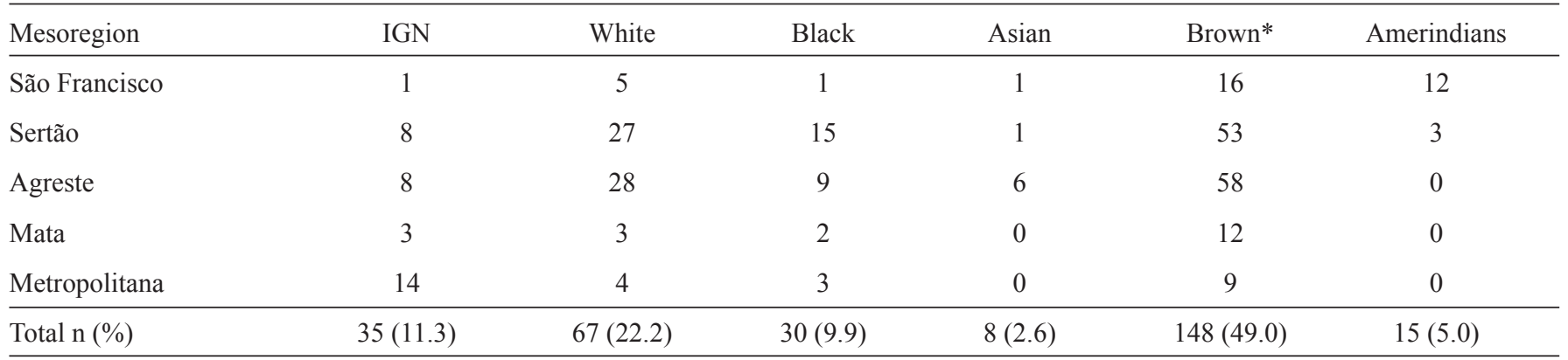

IGN: Ignored. *Brown-multiracial. 


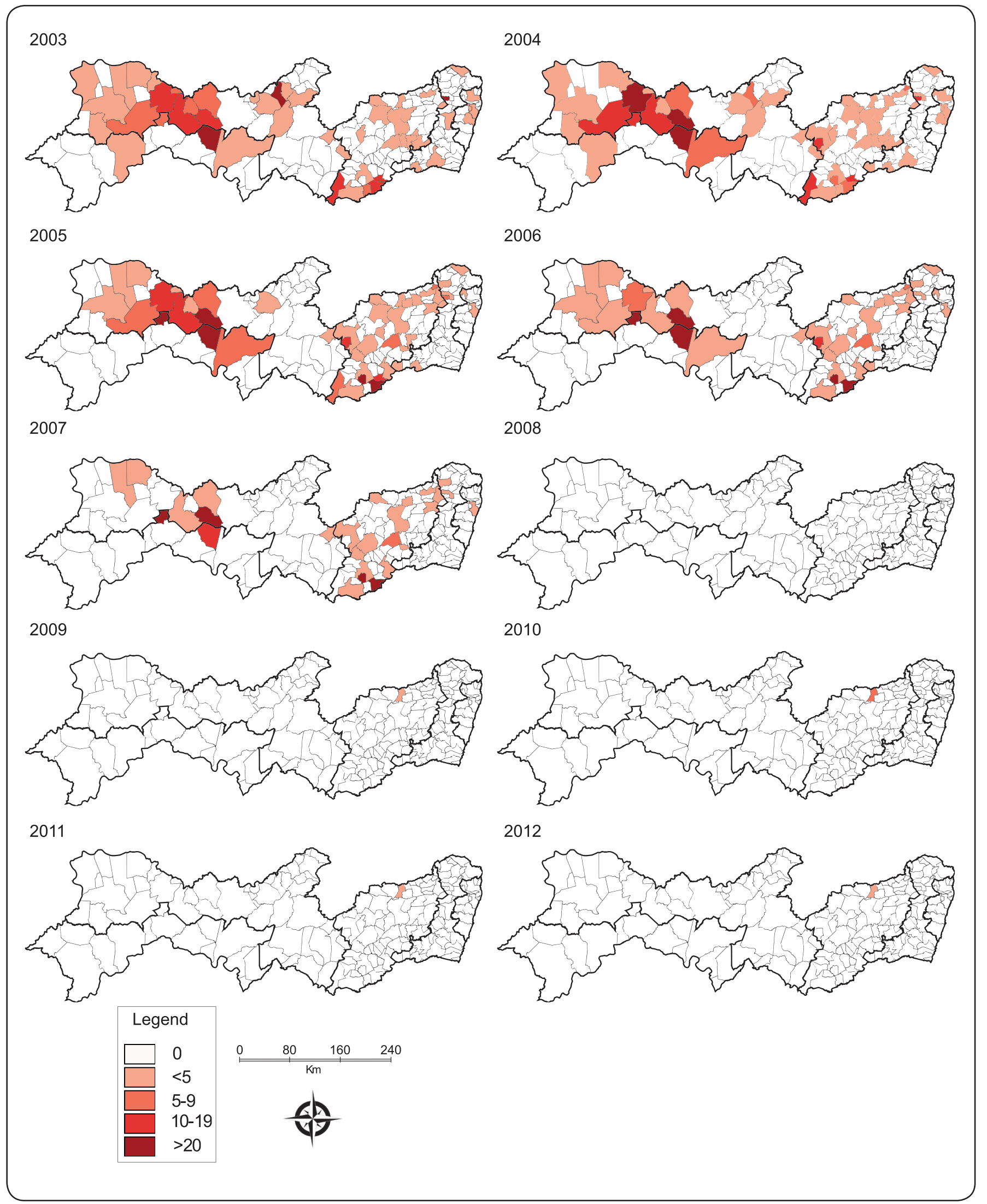

FIGURE 2 - Spatiotemporal distribution of acute Chagas disease rates in the State of Pernambuco from 2002 to 2013 , adopting the moving averages and municipalities as units of analysis. 
TABLE 2 - Municipalities in State of Pernambuco, Brazil that reported acute Chagas disease case rates $>36$ per 100,000 inhabitants from 2002-2013.

\begin{tabular}{|c|c|c|c|c|c|c|}
\hline Order & Municipality & Mesoregion & Micro-region & Population* & Cases** & Rates \\
\hline 2 & Mirandiba & 2 & $\mathrm{~b}$ & 13,547 & 22 & 162.40 \\
\hline 3 & Terra Nova & 1 & $\mathrm{c}$ & 8,756 & 8 & 91.37 \\
\hline 4 & Correntes & 3 & $\mathrm{~d}$ & 17,398 & 14 & 80.47 \\
\hline 6 & Brejão & 3 & d & 9,004 & 5 & 55.53 \\
\hline 7 & Carnaíba & 2 & $\mathrm{e}$ & 18,053 & 9 & 49.85 \\
\hline 8 & Lagoa do Carro & 4 & $\mathrm{f}$ & 14,934 & 7 & 46.87 \\
\hline 9 & Salgueiro & 2 & $\mathrm{~b}$ & 55,200 & 23 & 41.67 \\
\hline
\end{tabular}

Mesoregion: 1: São Francisco Pernambucano, 2: Sertão Pernambucano, 3: Agreste Pernambucano, 4: Mata Pernambucana. Micro-Region: a: Itaparica, b: Salgueiro, c: Petrolina, d: Garanhuns, e: Pajeú, f: Mata Setentrional Pernambucana, g: Vale do Ipojuca. *Mean population from 2001 to $2013 . * *$ Total of reported cases from 2001 to 2013.

between 2009 and 2012, except for in the municipality of Vertentes (Agreste Pernambucano mesoregion), which showed 3.66 reported cases per 100,000 inhabitants (Figures 2 - maps 2009, 2010, 2011 and 2012). The spatial distribution of reported acute Chagas disease cases throughout the period analyzed was heterogeneous with a high concentration in Carnaubeira da Penha and other cities of the Sertão and São Francisco Pernambucano mesoregions.

Table 2 depicts the demographic data and reported case rates of acute Chagas disease in the first 10 municipalities with 36 or more cases per 100,000 inhabitants in Pernambuco. The areas showing the highest rates are those located in the São Francisco and Sertão Pernambucano mesoregions, with up to 91 reported cases per 100,000 inhabitants (Table 2).

\section{DISCUSSION}

This is the first systematic spatiotemporal analysis of reported cases of acute Chagas disease in Pernambuco, Brazil. We identified spatial clusters of municipalities with high rates of Chagas disease, in particular an extended risk area comprising of ten municipalities. We noted priority areas for intervention, appropriate management of patients and effective measures to control and eliminate insect vectors.

The 2004 peak of acute cases reported in Pernambuco ( 7.32 cases per 1,000,000 inhabitants) may be explained by the higher importance given to Chagas disease in the $21^{\text {st }}$ century, a period in which the country intensified the strategies to eliminate T. infestans. Another study analyzing hospital admissions and mortality time series in Pernambuco revealed that the hospitalization rate for Chagas peaked in the same year, with a decrease in the subsequent years ${ }^{(13)}$. The peak may have trigged a greater commitment among health professionals to report acute cases. However, despite the decline in the number of acute cases, the parasite continues to circulate among human hosts.

Data analysis performed in this study shows that the data from Pernambuco are not reflective of Brazil as a whole with regard to the control of Chagas disease. This State shows a much higher rate of acute cases than the national rate between 2002 and 2006. However, a decline in the number of acute case notifications has been observed in Pernambuco over the years, indicating either successful prevention campaigns, underreported cases, or both. Conversely, an increased prevalence can be observed in the Amazon region, an endemic area that was previously considered to be non-endemic. This increased prevalence can be largely attributed to oral transmission through the consumption of natural products such as açaí and bacaba juice ${ }^{(14)(15)}$. In fact, between 1968-2005, a total of 437 cases of acute Chagas disease were reported in this region $^{(15)}$. Out of these, 311 were associated with 62 outbreaks in which the suspected mode of transmission was the consumption of açai ${ }^{(16)}$. The consumption of these products has encouraged the development of surveillance activities aimed at pasteurizing the products and controlling the export of untreated juice and other products to other regions in Brazil and to other countries $^{(17)}$.

The spatial distribution of acute Chagas disease was heterogeneous during the analyzed period. Indeed, cases were reported with either greater or lesser intensity in all of the Pernambuco mesoregions. The metropolitan region of Recife was the least affected area. These findings were expected because this area includes large cities with an infrastructure that may prevent the disease cycle. It is known that Chagas disease is a zoonosis that is transmitted in natural foci or ecological units within a well-defined geographical environment. The ecological unit is composed of either wild or domestic mammals and Triatoma bugs, both of which can be infected with T. cruzi 
and can be found in other mesoregions. In contrast, the Sertão and São Francisco Pernambucano mesoregions had the highest infection rates. Carnaubeira da Penha, for instance, had the highest incidence rate, with 217.98 individuals per 100,000 inhabitants affected. Differences among the municipalities may also be due to underreported cases associated with problems in the local health system, such as the lack of access to specialized services in these municipalities, leading to the migration of patients to nearby major centers ${ }^{(12)}$. This prevents health professionals from properly diagnosing Chagas disease and results in ineffective epidemiological surveillance services.

The report of acute Chagas disease cases in $37.8 \%$ of the municipalities of Pernambuco shows the potential transmission of $T$. cruzi in diverse phytogeographic regions, each with specific soil, vegetation, climate and topographical features. This distribution coincides with areas of Triatoma occurrence in Pernambuco, as observed by Silva and colleagues ${ }^{(18)}$. According to these authors, no infected triatomines were found in the metropolitan region of Recife, although $92.2 \%$ of identified instances of uninfected triatomines were within housing structures. However, in other mesoregions, infected triatomines were found in almost all of the municipalities, with a predominance of Triatoma brasiliensis, Triatoma pseudomaculata and Panstrongylus lutzi, thus maintaining the risk of T. cruzi transmission to humans in Pernambuco. These species are widely distributed, and infected specimens have been found inside houses. Even more alarming is the fact that $T$. infestans specimens were captured inside houses in one municipality (Lagoa Grande, São Francisco Pernambucano mesoregion); however, the insects were not infected ${ }^{(18)}$. These findings reveal the need to strengthen entomological surveillance programs that include routine house visitation by health agents, the stimulation of community involvement through educational campaigns, chemical control activities, and housing improvements in areas most affected by $T$. cruzi to reduce the risk of Chagas disease infection.

In contrast to what was observed in the State of Maranhão by Cutrim and colleagues in $2010^{(19)}$, our study did not show any differences between the number of infected males (43\%) and females (57\%). These authors found males to be the most infected, suggesting a sylvatic transmission cycle, as men are more likely to go into the forest to hunt or cultivate crops, thus increasing their exposition to the vector. As previously mentioned, different infected triatomine species have been found inside houses, putting men and women at the same risk of infection and corroborating our findings. As for the data regarding age groups, we observed that infection primarily afflicted adults aged between 20 and 59 years $(65.6 \%)$. This is relevant because the morbidity and mortality of acute Chagas disease is directly associated with a reduction in the quality of life of infected individuals. Through its impact on workforce productivity by causing premature disability and death, Chagas disease annually costs an estimated 667,000 disability-adjusted life years ${ }^{(20)(21)}$. In the case of Brazil alone, annually losses of over US $\$ 1.3$ billion in wages and industrial productivity were attributed to the disabilities of workers with Chagas disease ${ }^{(22)}$. Thus, prevention campaigns should be designed to target this demographic. Conversely, in the group of children aged up to 5 years, only two cases were reported (prevalence of $0.67 \%$ ), showing a low transmission rate within this group and highlighting the reduced vectorial transmission in Pernambuco after systematic and regular control programs against $T$. infestans. This is in accordance with a national survey to assess the seroprevalence of Chagas disease in 104,954 children aged up to 5 years that confirmed infection in only $32(0.03 \%)$ individuals ${ }^{(23)}$.

We conclude that even with successful control campaigns against $T$. infestans, monitoring activities for this disease are still required in Brazil, particularly in Pernambuco, where there are secondary (and domiciled) vector species, and other modes of transmission such as ingestion of contaminated beverage and food or congenital transmission remain common.

\section{CONFLICT OF INTEREST}

The authors declare that there is no conflict of interest.

\section{REFERENCES}

1. Steindel M, Kramer Pacheco L, Scholl D, Soares M, de Moraes MH, Eger I, et al. Characterization of Trypanosoma cruzi isolated from humans, vectors, and animal reservoirs following an outbreak of acute human Chagas disease in Santa Catarina State, Brazil. Diagn Microbiol Infect Dis 2008; 60:25-32.

2. Amato Neto V, Lopes M, Umezawa ES, Aveiro Ruocco MS, Dias JC. Outras formas de transmissão do Trypanosoma cruzi. Rev Patol Trop 2000; 29 (supl I):115-129.

3. Coura JR, Viñas PA. Chagas disease: a new worldwide challenge. Nature 2010; 465:S6-S7.

4. Organización Panamericana de la Salud (OPAS). Estimación cuantitativa de la enfermedad de Chagas en las Americas. Montevideo, Uruguay: OPAS; 2006.

5. Schmunis GA, Yadon ZE. Chagas disease: a Latin American health problem becoming a world health problem. Acta Trop 2010; 115:14-21.

6. Dias JC. Southern Cone Initiative for the elimination of domestic populations of Triatoma infestans and the interruption of transfusion Chagas disease: historical aspects, present situation, and perspectives. Mem Inst Oswaldo Cruz 2007; 102:11-18.

7. Lannes-Vieira J, Soeiro Mde N, Corrêa-Oliveira R, Araújo-Jorge TC. Chagas disease centennial anniversary celebration: historical overview and prospective proposals aiming to maintain vector control and improve patient prognosis-a permanent challenge. Mem Inst Oswaldo Cruz 2009; 104 (supl I):5-7.

8. Moncayo A, Silveira AC. Current epidemiological trends for Chagas disease in Latin America and future challenges in epidemiology, surveillance and health policy. Mem Inst Oswaldo Cruz 2009; 104 (supl I):17-30.

9. World Health Organization (WHO). Chagas disease, Brazil. Interruption of transmission. WHO 2000; 75:153-160.

10. Nascimento LF, Batista GT, Dias NW, Catelani CS, Becker D, Rodrigues L. Análise espacial da mortalidade neonatal no Vale do Paraíba, 1999 a 2001. Rev Saude Publica 2007; 41:94-100.

11. Khan OA, Davenhall W, Ali M, Castillo-Salgado C, VazquezProkopec G, Kitron U, et al. Geographical information systems and tropical medicine. Ann Trop Med Parasitol 2010; 104:303-318. 
12. Martins-Melo FR, Alencar CH, Ramos Jr AN, Heukelbach J. Epidemiology of mortality related to Chagas' disease in Brazil, 1999-2007. PLoS Negl Trop Dis 2012; 6:e1508.

13. Braz SC, Melo MF, Lorena VM, Souza WV, Gomes YM. Chagas disease in the State of Pernambuco, Brazil: analysis of admissions and mortality time series. Rev Soc Bras Med Trop 2011; 44:318-323.

14. Beltrão HB, Cerroni MP, Freitas DR, Pinto AY, Valente VC, Valente SA, et al. Investigation of two outbreaks of suspected transmission of acute Chagas disease in the Amazon region, Para State, Brazil, in 2007. Trop Doct 2009; 39:231-232.

15. Nóbrega AA, Garcia MH, Tatto E, Obara MT, Costa E, Sobel J, et al. Oral transmission of Chagas disease by consumption of açaí palm fruit, Brazil. Emerg Infect Dis 2009; 15:653-655.

16. Valente SA, Valente VC, Pinto AY. Epidemiologia e transmissão oral da doença de Chagas na Amazônia brasileira. In: Informe de la consulta técnica em epidemiologia, prevencion y manejo de la transmision de la enfermidad de Chagas como enfermidad transmitida por alimentos (ETA). Washington: Organizacion Panamericana de La Salud/Organizacion Mundial de La Salud; 2006. p. 21-26.

17. Martins-Melo FR, Ramos AN, Alencar CH, Heukelbach J. Prevalence of Chagas disease in Brazil: a systematic review and meta-analysis. Acta Trop 2014; 130:167-174.
18. Silva MB, Barreto AV, Silva HA, Galvão C, Rocha D, Jurberg J, et al. Synanthropic triatomines (Hemiptera, Reduviidae) in the State of Pernambuco, Brazil: geographical distribution and natural Trypanosoma infection rates between 2006 and 2007. Rev Soc Bras Med Trop 2012; 45:60-65.

19. Cutrim FS, Almeida IA, Gonçalves EG, Silva AR. Doença de Chagas no Estado do Maranhão, Brasil: registro de casos agudos no período de 1994 a 2008. Rev Soc Bras Med Trop 2010; 43:705-708.

20. Mathers CD, Ezzati M, Lopez AD. Measuring the burden of neglected tropical diseases: the global burden of disease framework. PLoS Negl Trop Dis 2007; 1:e114.

21. Ribeiro I, Sevcsik AM, Alves F, Diap G, Don R, Harhay MO, et al. New, improved treatments for Chagas disease: from the R\&D pipeline to the patients. PLoS Negl Trop Dis 2009; 3:e484.

22. Moncayo A, Ortiz Yanine MI. An update on Chagas disease (human American trypanosomiasis). Ann Trop Med Parasitol 2006; 100:663-677.

23. Ostermayer AL, Passos AD, Silveira AC, Ferreira AW, Macedo V, Prata AR. O inquético nacional da soroprevalência de avaliação do controle da doença de Chagas no Brasil (2001-2008). Rev Soc Bras Med Trop 2011; 44 (supl II):108-121. 